\title{
A functional-structural coral model
}

\author{
$\underline{\text { A.K. Cresswell }}^{\mathrm{a}, \mathrm{b}}$, D. P. Thomson ${ }^{\mathrm{a}}$, E.J. Trevenen ${ }^{\mathrm{b}, \mathrm{c}}$ and M. Renton $^{\mathrm{b}, \mathrm{c}}$ \\ ${ }^{a}$ Oceans and Atmosphere, Commonwealth Scientific and Industrial Research Organisation (CSIRO) \\ ${ }^{b}$ School of Biological Sciences, The University of Western Australia \\ ${ }^{c}$ School of Agriculture and Environment, The University of Western Australia \\ Email: anna.cresswell@csiro.au
}

\begin{abstract}
In biological systems, structural complexity is recognized as an important driver of coexistence and species diversity. This is particularly true for coral reefs, where some of the most biodiverse life on Earth coexists. A key contributor to reef structural complexity is the varied morphologies into which reef corals can grow. A large number of coral species of different forms can be found on a typical reef system, and, as well, individual species may show high plasticity in growth morphology in response to the local environmental conditions. As environmental conditions and disturbances regimes shift with climate change, future coral reef assemblages are in question.
\end{abstract}

Many corals respond to light in a comparable ways to plants, due to the presence of symbiotic algae in the cells of the animals that photosynthesise and it is well established that corals respond to their environment (e.g. light) by adjusting their morphology. Corals have very slow growth rates and field observations capturing growth and competition are therefore difficult. As such, a modelling approach provides a much needed opportunity to explore changes in coral structure and functioning. Here, we adapt a functionalstructural plant modelling approach, commonly used in plant sciences, to represent coral colonies. Functional-structural modelling combines functional components, such as photosynthesis, growth rates, transport of resources and responses to environmental parameters, with a dynamic representation of the 3D structure or architecture of the modelled plant(s), or in this case, corals.

The aim was to create a 3D functional-structural model where structure, function and response to local environmental factors are specified by a set of 'morpho-functional' parameters, and determine whether this model could represent some of the major coral growth forms seen on coral reefs. Understanding the growth, competition and mortality of organisms at a three-dimensional (3D) level is important in understanding an organism's role as an engineering species and the mechanisms that lead to the maintenance of structural integrity.

The results show that the model can simulate corals with distinct morphologies by varying the simple set of morpho-functional parameters, including resources required for growth, self-avoidance and resource sharing. From varying these parameters, coral morphologies emerge that match with observed coral shapes in nature that are known to have different growth rates and structural fragility. These include hemispherical, encrusting, columnar and tabular forms.

The full diversity of morphologies is not yet captured, and further investigation into other parameters is required. There are many potential future applications of this functional-structural coral model, including matching model output at a coral community level to field measurements from a real coral community. If the model can represent real morphological assemblages for different environmental conditions it could be used to predict future assemblages under different climatic disturbance regimes.

Keywords: Cellular automaton, coral reef, functional diversity, polyp, structural complexity 


\section{INTRODUCTION}

Found in much of the world's shallow tropical oceans, corals (phylum Cnidaria, class Anthozoa) are sessile organisms which form colonies constructed from building blocks known as polpys (Hughes et al., 1992). Polyps contain digestive and reproductive tissues with the 'reef building' corals also containing zooxanthellae, singlecelled microalgae that photosynethesise (phylum Dinoflagellata). The polyp and the zooxanthella have a symbiotic relationship, the zooxanthella exchanging light energy for nutrients and protection. Using light energy, as well as food from filter feeding, the polyp calcifies, whereby it secrets a calcium carbonate 'skeleton'. Polyps are connected by living tissue, through which organic products are transported (Maguire \& Porter, 1977). Collectively, coral colonies form a coral reef, the underlying foundation of which is a build-up of dead coral skeletons with the living reef growing over the top. Growth of corals is a function of the repeated addition of coral polyp modules to the colony (Dornelas et al., 2017), and is therefore a good candidate for cellular automaton stochastic modelling.

Two-dimensional modelling has been used to investigate coral dynamics and disturbance (Horwitz et al., 2017), competition (Johnson \& Seinen, 2002), community composition (Maguire \& Porter, 1977), calcification rates and reef zonation (Graus et al., 1984). Work by Kaandorp et al. (2011) tackled coral growth in three-dimensions (3D) in fine detail. These sophisticated models considered light, diffusion of nutrients and the formation of different shapes via accretive growth. These models demonstrated how a computational 3D approach can help to understand the complex growth of modular organisms, though the focus was largely been on reproducing observed coral morphologies at a single colony level. Here, we have chosen to develop a less complex 3D model with the aim of modelling not just single colonies, but a community of different corals growing and interacting. This is timely given that new photographic meshing technology is allowing collection and quantification of intricate 3D features of communities of corals (Gutierrez-Heredia et al., 2016).

A diverse array of coral shapes and sizes exists in a coral reef community. The structural complexity that results has been shown to be very important in generating high biodiversity, productivity, and functionality in reef associated fauna (Graham et al., 2007; Wilson et al., 2010). In addition to approximately 800 extant hard coral species with diverse shapes described globally (Foden et al., 2013), at an intra-species level, high plasticity in growth form is common. Such morphological plasticity is believed to be an adaptation of sessile growth that evolved to allow an organism to best exploit the microenvironment in which it grows (Bradshaw, 1965). Corals adjust their shape to conform to hydrodynamic and light conditions (Lartaud et al., 2015) and amplified hydrodynamic environments will cause selective mortality associated with shape and density of the coral skeleton.

Corals have been classified according to the Grime (1988) competitive, ruderal and stress-tolerant functional groups and, more recently, this has been expanded to a coral trait classification which incorporates more coral specific characteristics such as morphology, vulnerability to stress and life history strategies (e.g. growth rate or fecundity) (Madin et al., 2016). The trait based classification is suggested to offer new insights into patterns of function and diversity on coral reefs and to provide a more mechanistic understanding of how coral communities respond to environmental change (Darling et al., 2012; Madin et al., 2016). Climate change, associated with predictions of increased disturbance regimes, threatens to drastically alter the composition of corals on coral reefs.

Typical morphological classifications of corals include tabular, hemispherical, columnar and encrusting (Fig. 1) and, generally, these groups are known to have differences in growth rates and vulnerability to disturbances, with a broad trade-off between fast growing, competitive species being more vulnerable to disturbance, and slower growing species being stress-tolerant. Figure 1 does not represent the full set of observed coral morphologies (see Pratchett et al. (2015)) but were the forms we first aimed to capture with the model. The primary aim of the functional-structural coral model developed here was to determine whether simple local variables and functional type parameters can recreate the range of major coral shapes observed in nature. Space and light, the main limiting resources for which corals compete on a healthy coral reef (Kaandorp et al., 2011; Dornelas et al., 2017), are built into the model.
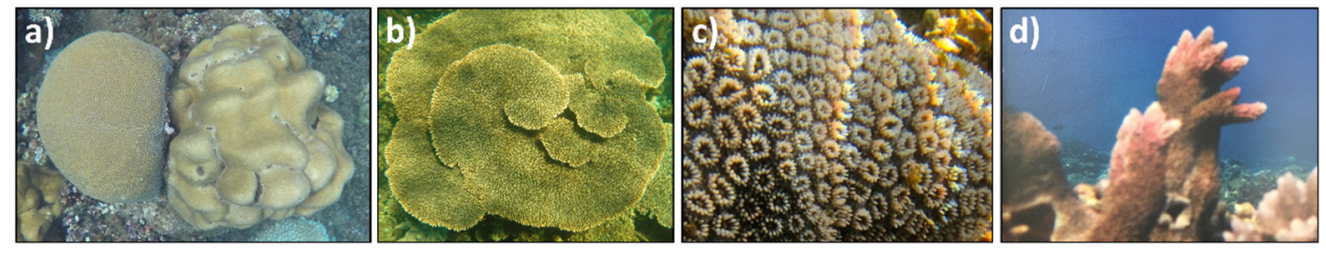

Figure 1. Four typical coral morphological groups: a) hemispherical/ massive, b) tabular, 


\subsection{Overview}

A cellular automaton (Chopard \& Droz, 1998) stochastic model was used to simulate the 3D growth of coral colonies communities through time in R (R Core Team, 2017). Coral growth is suited to this method because corals have modular architecture resulting from the iteration of a single unit, the polyp (Lartaud et al., 2015). We model at the colony level, but implicitly consider each occupied cell in the model to be a bundle of polyps which may grow into an adjacent cell once in a time-step, allowing multidimensional growth of the coral colony. The time-step can be varied but is set at two weeks, given that corals are slow growing organisms $(0.005$ $-0.07 \mathrm{~m} \mathrm{yr}^{-1}$ ) and therefore this time is sufficient to capture the dynamic growth, i.e. 26 time steps per $0.005-$ $0.07 \mathrm{~m}$ of growth.

The model represents coral growth and development inside a volume of water, the 'world', with flexible dimensions in $\mathrm{x}, \mathrm{y}, \mathrm{z}$ space, here set to be $1 \mathrm{~m}^{3}$, representing a section of the reef with the third dimension representing the depth of the water column. The cuboid was divided into $1 \mathrm{~cm}^{3}$ voxels which were the lowest spatial unit upon which growth and light attenuation were governed. The world is wrapped on the sides, while the bottom of the world (representing the seafloor) and the top of the world (representing the water surface) are limits of growth. For full details, the model code is available on request to the authors.

\section{$2.2 \quad$ Light}

Light is modelled relatively simply, and although a more sophisticated model is possible, we believe the current approach is sufficient to simulate the required effects of light absorption and shading by the simulated corals. A constant amount of light is assumed to enter the water surface, with a gradient attenuating from the surface with depth in $1 \mathrm{~cm}$ layers based on an approximation that $44 \%$ of surface light reaches $1 \mathrm{~m}$ depth in seawater. This percentage may be changed in future versions to account for different water quality conditions, i.e. in turbid water less light will reach a set depth, or in clear conditions, there will be greater light attenuation. To achieve this in the model, $0.8 \%$ of the light is assumed to be lost per each $1 \mathrm{~cm}$ of depth. Of the light that passes through a $1 \mathrm{~cm}$ voxel, $40 \%$ is assumed to travel straight down to the voxel immediately below and the remaining $60 \%$ is spread evenly among the four neighbouring voxels. Once voxels are occupied by coral they
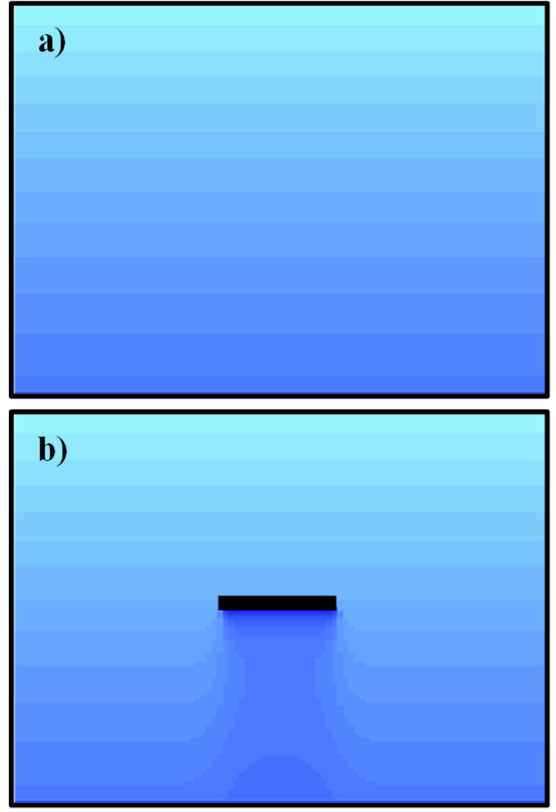

Figure 2. a) Initial light shown through a cross section of the world (lighter blue $=$ greater light). Light is greatest at the surface and attenuates with depth. b) Light shown in a situation where an obstruction will absorb all light entering that voxel. This allows shading to occur (Fig. 2).

\subsection{Morpho-functional parameters}

There are 11 morpho-functional parameters currently used in the model (Table 1).

Table 1. Morpho-functional parameters and their meaning in the model.

\begin{tabular}{|l|l|l|}
\hline Morpho-functional parameter & Meaning \\
\hline $\begin{array}{l}\text { Resources/ } \\
\text { resource } \\
\text { allocation }\end{array}$ & Required resources, $r_{g}$ & $\begin{array}{l}\text { A unitless measure of the amount of resources which must be } \\
\text { accumulated before growth will occur }\end{array}$ \\
\cline { 2 - 3 } & Density, $\rho$ & $\begin{array}{l}\text { Resource to volume conversion: a greater amount of resources used } \\
\text { equates to a higher density cell being created }\end{array}$ \\
\cline { 2 - 3 } & Daughters, $g_{\text {daughter }}$ & Chance of a single cell growing multiple times \\
\hline \multirow{3}{*}{$\begin{array}{l}\text { Directional } \\
\text { growth }\end{array}$} & Upwards growth tendency, $g_{\text {up }}$ & Tendency to grow up rather than out \\
\cline { 2 - 3 } & $\begin{array}{l}\text { Ontogenetic upwards growth tendency } \\
\text { change, } g_{\text {up, age }}\end{array}$ & Change in upwards growth tendency with colony age \\
\cline { 2 - 3 } & Light seeking, $g_{\text {light }}$ & Tendency to grow toward empty voxels which have greater light levels \\
\hline \multirow{2}{*}{ Avoidance } & Self-avoidance, $g_{a}$ & Tendency to avoid a neighboring coral cell \\
\cline { 2 - 3 } & Self-avoidance distance, $g_{a, \text { dist }}$ & Number of voxels avoided between another coral \\
\hline Sharing & Resource sharing, $s_{r}$ & Proportion of resources shared with adjacent living cells \\
\cline { 2 - 3 } & Directional resource sharing (light), $s_{\text {light }}$ & Tendency to move resources towards adjacent cells with higher light \\
\cline { 2 - 3 } & Resource sharing child, $s_{\text {daughter }}$ & Proportion of resources given to daughter cell \\
\hline
\end{tabular}

The morpho-functional parameters are categorised into 'resources', 'directional growth, 'avoidance' and

'sharing' parameters that govern the likelihood and direction of growth occurring in each time-step. Each initial 
cell that populates the model is allocated a full set of parameters. The 'daughter' is the name given to any new cell created by a specific existing cell.

\section{$2.4 \quad$ Stochastic growth}

Figure 3 summarises the progression of the model in schematic form. Coral recruits are parameterized (see Table 1) prior to entering the world where they are randomly placed at the base of the world and begin responding to the light environment and growing. For simplicity, growth is constrained to the 3D von Neumann neighbourhood. Each cell, if it has sufficient energy for growth (obtained from light absorption), may grow into any empty voxel in the neighbourhood surrounding it. In each time-step all six neighbouring voxels are checked for (1) whether they are already occupied by coral, and (2) their light level. Depending on the morpho-functional parameters the polyp may grow with more probability towards light or space (see Table 1).

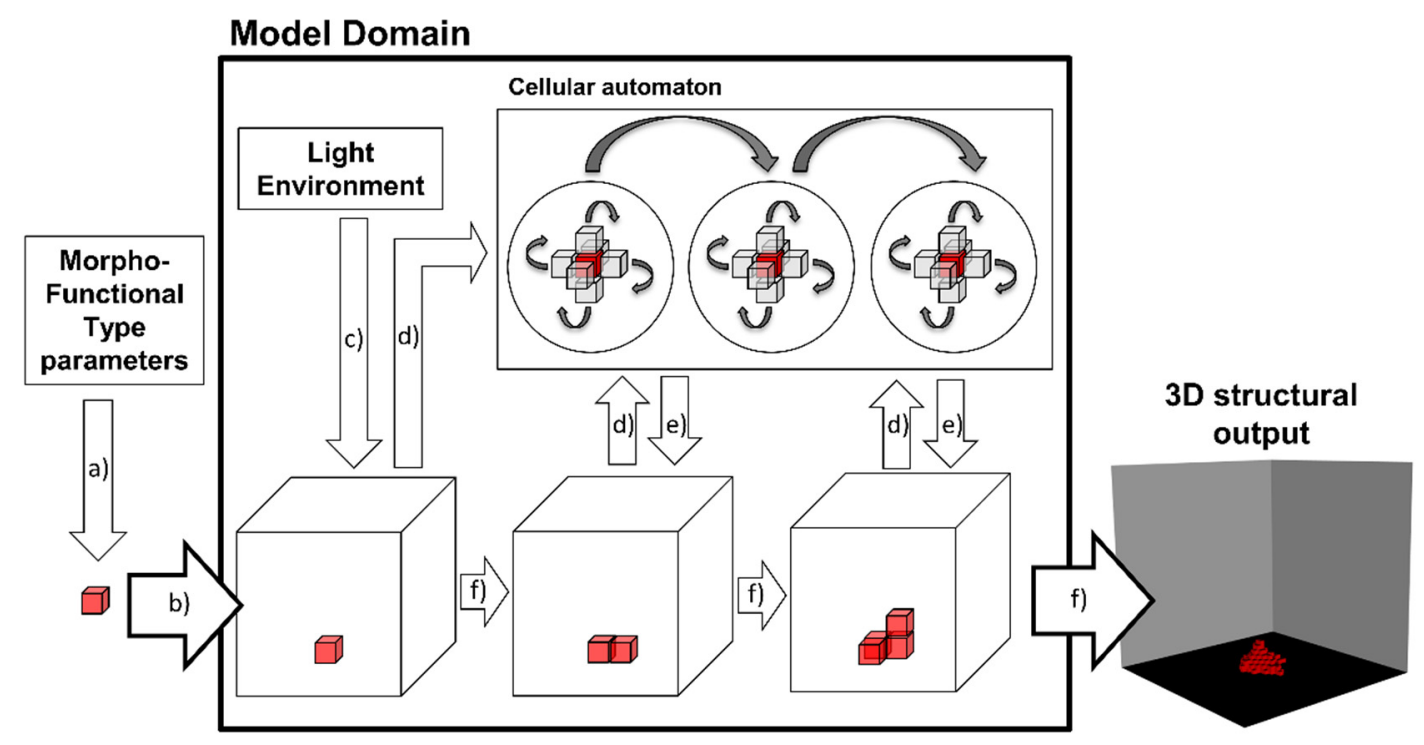

Figure 3. A simplified schematic breakdown of the model. The red cubes represent $1 \mathrm{~cm}^{3}$ voxels filled with coral mass, the lowest spatial unit in the model upon which growth and light attenuation was governed. At (a) one (or multiple) cells are parametertised for a given morpho-functional type. At (b) the initial polyps enter the model domain which has a light environment (c) which is highest at the surface and attenuates with depth. In (d) the amount of energy each cell has is considered as well as the availability of neighbouring voxels: whether they are empty and how much light they have. This impacts the direction of growth, which is also dependent on the morpho-functional parameters of the cell. If growth occurs, an additional cell is added to the model (e). Over multiple time-steps (f) 3D growth is achieved.

A set of variables for each cell occupied by a coral are tracked in every time-step and stored in a dataframe with length equal to the number of occupied cells (Table 2). This includes the size (a cell may not occupy the full cell space when it first grows), and age of a cell. A cell may only grow into a neighbouring cell when it has enough resources and has filled the entire cell space, i.e. full size. The number of occupied neighbours is tracked, as well as the amount of light absorbed by a cell. Corals often experience partial mortality, where sections of the coral colony may die while the coral colony as a whole continues to grow and survive (Nugues \& Roberts, 2003). To represent this in the model, an occupied cell can be alive or dead. Death of a coral cell occurs if its resources fall below zero.

3. SIMULATIONS AND RESULTS
Table 2. Tracked variables for each occupied cell in the model at each time-step

\begin{tabular}{|l|l|}
\hline Variable & Meaning \\
\hline Resources & $\begin{array}{l}\text { The amount of resources, or energy, a cell has for } \\
\text { growth. Light absorption increases resources while } \\
\text { resources are used for growth and general } \\
\text { maintenance. }\end{array}$ \\
\hline Size & $\begin{array}{l}\text { Growth is set so that a cell is not fully occupied, } \\
\text { rather, gradually fills. Size is the proportion of a cell } \\
\text { that is filled. }\end{array}$ \\
\hline Age & $\begin{array}{l}\text { The time since a cell was first filled with } \\
\text { coral (at a given time step) }\end{array}$ \\
\hline $\begin{array}{l}\text { Light } \\
\text { uptake }\end{array}$ & $\begin{array}{l}\text { How much light a cell absorbs in a given time-step. } \\
\text { Neighbours }\end{array}$ \\
$\begin{array}{l}\text { Six possible neighbours in the 3D Von Neumann } \\
\text { neighbourhood are tracked for whether they are } \\
\text { occupied or empty space. }\end{array}$ \\
\hline Dead/ alive & $\begin{array}{l}\text { An occupied cell can be alive or dead, dying if its } \\
\text { resources fall below zero. If dead it can no longer } \\
\text { grow and resources will not be shared with it. }\end{array}$ \\
\hline
\end{tabular}


Four sets of morpho-functional parameters were trialled with the aim of recreating four of the major coral growth forms. Parameters were estimated with reference to the literature on the growth rates and resource sharing of different types of corals (Pratchett et al. 2015, Darling et al. 2012). Four major morphologies emerged from trialling different combinations of morpho-functional parameters (Fig. 4a). These matched observed coral morphologies common in natural reef systems: encrusting, hemispherical, tabular and columnar. A branching growth form matching those seen in nature did not emerge from the set of parameter combinations that were trialled, though the columnar form was closest. Figure $4 \mathrm{~b}$ shows the light absorption of the four morphologies in Figure 4a. The different morphologies show clear differences in light absorption (Fig. 4b). The hemispherical colony (i) resembles the mottled surface seen in real corals and it is evident that even small irregularities in surface texture can cause differences in the light absorption from cell to cell. The tips of the tallest coral, the columnar (iii), absorb the most light while the tabular coral (ii) absorbs across the whole surface of its table in a similar way to the encrusting coral (iv) but the table causes shading at the base.
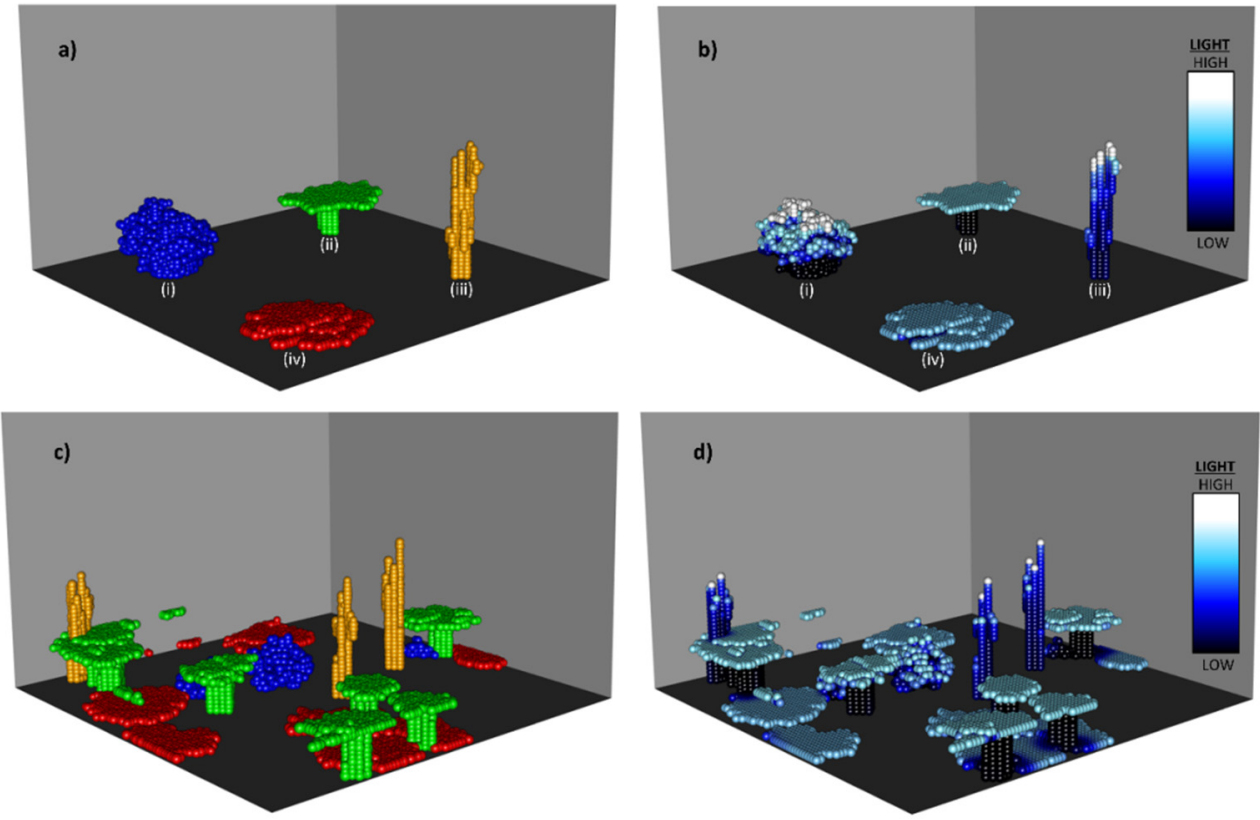

Figure 4. Model output presented using the $r g l$ package (Adler et al. 2017) for R (a) Four growth forms emergent from different combinations of morpho-functional parameters: (i) shows the formation of a massive/ hemispherical colony (blue), (ii) the formation of a tabular coral (green), (iii) the formation of a columnar coral (orange) and (iv) the formation of an encrusting coral (red). (b) Light absorption for the same growth forms in a). (c) Model output shown for 20 corals showing tabular forms in green, hemispherical in blue, encrusting in red, and columnar in orange. (d) shows the same community of corals in the same time-step coloured according to the amount of light they are absorbing at that location.

Twenty recruits (cells in the model) were randomly allocated parameters that formed one of the four main morphologies in Figure 4a. Each were randomly placed at the base of the world to investigate light and shading in a community of corals growing through time. The simulation was run for 72 two-week time-steps (3 years). Figure $4 \mathrm{c}$ shows a resultant coral community as an assemblage of variations of the four morphologies. The differences in forms among the four morphologies reflects response to their specific microenvironment and random chance. Figure $4 \mathrm{~d}$ shows the same community of corals and the amount of light each is absorbing. It is clear that the tabular and columnar forms in particular have an advantage in capturing greater light, particularly relative to the encrusting corals, where over-shading occurs.

\section{CONCLUSIONS AND RECOMMENDATIONS}

Here we have presented the first edition of a model capable of capturing different growth forms of corals in a community. We have demonstrated how a relatively simple cellular automaton model with a local light environment that creates shading can recreate some of the major coral morphologies seen on natural coral reefs. At the community level we were able to observe how some morphologies, viz. tabular and columnar, have strategic advantages in capturing light.

Whilst we were able to recreate several common coral growth forms - tabular, encrusting, hemispherical and columnar - parameters were trialled to investigate branching growth and this did not emerge in a form that matched the morphologies observed in nature. Unlike the other growth forms, branching in corals is a complex 
process, quite distinct from the growth of other coral shapes (Merks et al., 2004). However, such branching growth has been successfully captured through considering polyp-orientation and consideration of diffusion of nutrients (Merks et al., 2004; Kaandorp et al., 2011). Our future work will take a simplified version of this approach to simulate branching growth forms. To better match real coral reef environments, we recommend adding in nutrients and hydrodynamics to the model, two additional local variables that will impact coral growth and colony survival (Merks et al., 2004; Madin \& Connolly, 2006). This would allow greater capacity to investigate the competitive strategies and morphological plasticity of different coral growth forms.

At present the model has been run to investigate growth and shading over a short time (3 years). However, with the addition of nutrient and hydrodynamic variables, the model will be better capable of capturing the multigenerational progression of a coral community. Disturbances that cause coral mortality and removal can then be considered, as well as the process of coral reproduction (via sexual reproduction (Darling et al., 2012) and asexual reproduction (Lirman, 2003)). This would allow fuller consideration of the trade-offs between growth and competition strategies over longer time periods and variable disturbance regimes.

Coral reefs are presently in danger of changing drastically in composition, or disappearing altogether, due to human impacts, ocean acidification, and the biggest threat, elevated water temperatures (Hughes et al., 2017). There are still major unknowns about whether some coral species may be able to survive these changes. To use the model to address this question, and make it usable as a predictive tool, it should be parameterized for a number of reef systems and run through time (considering past disturbances) to test whether the morphological composition of the model output can be matched to real reef assemblages. If this is achieved the questions that could be asked of the model are numerous and would include predictions of future assemblages under different disturbance regimes. However, the parameters used here to create the four main growth forms may not be the only biologically relevant or realistic set of parameters than can create these structures. Alternative parameterisations should be considered in future work, as well as the sensitivity of the model to the parameters used.

The majority of climate change projections show a future characterised by increases in the frequency, and possibly severity, of many forms of climatic disturbances such as cyclones and heat waves (Hughes et al., 2017). Selective mortality of different shapes and sizes of corals due to such events has been well documented, for example Woodley et al. (1981) found tabular and branching morphologies to be reduced by up to $99 \%$ following a cyclone, while hemispherical growth forms by only $9 \%$. As well, Hughes and Connell (1999) found that damage due to cyclones on the Great Barrier Reef was $42 \%$ for tabular and only $4 \%$ for hemispherical growth forms. Branching Acropora spp., recognized as the fastest growing coral group, are particularly vulnerable to anomalous high temperatures. These disparities can be considered in a future versions of the model run over multi-year periods. The role of day-to-day conditions (e.g. wave energy, light availability) versus large-scale acute events (cyclones or large swell) that may alter coral reef structure drastically and rapidly could also be considered.

Here, we consider corals interacting and competing. On a real coral reef system other organisms such as macroalgae, turf algae and coralline algae can be key competitors for space. With the current investigation being about coral competition and assemblage it has not been deemed necessary to consider these other sessile organisms, however, to take a broader ecosystem perspective, this could be considered.

There are many potential future applications of the model, some of which have been discussed. This functionalstructural coral model forms the foundation for developing a more comprehensive model to consider more detailed questions on competition and survival in coral reefs at a functional level.

\section{ACKNOWLEDGEMENTS}

We acknowledge the support of the BHP-CSIRO Ningaloo Outlook Marine Research Partnership and thank Dirk Slawinski (CSIRO) for discussions of 3D modelling and Melanie Trapon (CSIRO) for discussions of coral physiology.

\section{REFERENCES}

Adler, D., Murdoch, D. et al. (2017). rgl: 3D Visualization Using OpenGL. R package version 0.98.1. https://CRAN.R-project.org/package=rgl

Bradshaw, A.D. (1965). Evolutionary significance of phenotypic plasticity in plants. Advances in genetics, 13, (115-155).

Chopard, B. \& Droz, M. (1998). Cellular automata. Springer

Darling, E.S., Alvarez-Filip, L., Oliver, T.A., McClanahan, T.R. \& Côté, I.M. (2012). Evaluating life-history strategies of reef corals from species traits. Ecology Letters, 15(12), 1378-1386. 
Dornelas, M., Madin, J.S., Baird, A.H. \& Connolly, S.R. (2017). Allometric growth in reef-building corals. Proceedings of the Royal Society B, p. 20170053.

Foden, W.B., Butchart, S.H., Stuart, S.N., Vié, J.-C., Akçakaya, H.R., Angulo, A., DeVantier, L.M., Gutsche, A., Turak, E. \& Cao, L. (2013). Identifying the world's most climate change vulnerable species: a systematic trait-based assessment of all birds, amphibians and corals. PloS one, 8(6), e65427.

Graham, N.A., Wilson, S.K., Jennings, S., Polunin, N.V., Robinson, J., Bijoux, J.P. \& Daw, T.M. (2007). Lag effects in the impacts of mass coral bleaching on coral reef fish, fisheries, and ecosystems. Conservation biology, 21(5), 1291-1300.

Graus, R.R., Macintyre, I.G. \& Herchenroder, B.E. (1984). Computer simultion of the reef zonation at Discovery Bay, Jamaica: Hurricane disruption and long-term physical oceanographic controls. Coral Reefs, 3(2), 59-68.

Grime, J.P. (1988). The CSR model of primary plant strategies-origins, implications and tests. Plant evolutionary biology, pp. 371-393. Springer.

Gutierrez-Heredia, L., Benzoni, F., Murphy, E. \& Reynaud, E.G. (2016). End to End Digitisation and Analysis of Three-Dimensional Coral Models, from Communities to Corallites. PloS one, 11(2), e0149641.

Horwitz, R., Hoogenboom, M.O. \& Fine, M. (2017). Spatial competition dynamics between reef corals under ocean acidification. Scientific Reports, 7, 40288.

Hughes, T. \& Connell, J. (1999). Multiple stressors on coral reefs: a long-term perspective. Limnology and oceanography, 44(3), 932-940.

Hughes, T.P., Ayre, D. \& Connell, J.H. (1992). The evolutionary ecology of corals. Trends in Ecology \& Evolution, 7(9), 292-295.

Hughes, T.P., Kerry, J.T., Álvarez-Noriega, M., Álvarez-Romero, J.G., Anderson, K.D., Baird, A.H., Babcock, R.C., Beger, M., Bellwood, D.R. \& Berkelmans, R. (2017). Global warming and recurrent mass bleaching of corals. Nature, 543(7645), 373-377.

Johnson, C.R. \& Seinen, I. (2002). Selection for restraint in competitive ability in spatial competition systems. Proceedings of the Royal Society of London B: Biological Sciences, 269(1492), 655-663.

Kaandorp, J.A., Filatov, M. \& Chindapol, N. (2011). Simulating and Quantifying the Environmental Influence on Coral Colony Growth and Form. Coral Reefs: An Ecosystem in Transition (ed. by Z. Dubinsky and N. Stambler), pp. 177-185. Springer Netherlands, Dordrecht.

Lartaud, F., Galli, G., Raza, A., Priori, C., Benedetti, M.C., Cau, A., Santangelo, G., Iannelli, M., Solidoro, C. \& Bramanti, L. (2015). Growth Patterns in Long-Lived Coral Species. Marine Animal Forests: The Ecology of Benthic Biodiversity Hotspots (ed. by S. Rossi, L. Bramanti, A. Gori and C. Orejas Saco Del Valle), pp. 1-32. Springer International Publishing, Cham.

Lirman, D. (2003). A simulation model of the population dynamics of the branching coral Acropora palmata Effects of storm intensity and frequency. Ecological modelling, 161(3), 169-182.

Madin, J.S. \& Connolly, S.R. (2006). Ecological consequences of major hydrodynamic disturbances on coral reefs. Nature, 444(7118), 477-480.

Madin, J.S., Hoogenboom, M.O., Connolly, S.R., Darling, E.S., Falster, D.S., Huang, D., Keith, S.A., Mizerek, T., Pandolfi, J.M. \& Putnam, H.M. (2016). A trait-based approach to advance coral reef science. Trends in ecology \& evolution, 31(6), 419-428.

Maguire, L.A. \& Porter, J.W. (1977). A spatial model of growth and competition strategies in coral communities. Ecological Modelling, 3(4), 249-271.

Merks, R.M.H., Hoekstra, A.G., Kaandorp, J.A. \& Sloot, P.M.A. (2004). Polyp oriented modelling of coral growth. Journal of Theoretical Biology, 228(4), 559-576.

Nugues, M.M. \& Roberts, C.M. (2003). Partial mortality in massive reef corals as an indicator of sediment stress on coral reefs. Marine Pollution Bulletin, 46(3), 314-323.

Pratchett, M.S., Anderson, K.D., Hoogenboom, M.O., Widman, E., Baird, A.H., Pandolfi, J.M., Edmunds, P.J. \& Lough, J.M. (2015). Spatial, temporal and taxonomic variation in coral growth-implications for the structure and function of coral reef ecosystems. Oceanography and Marine Biology: An Annual Review, 53, 215-295.

R Core Team (2017). R: A language and environment for statistical computing. $R$ Foundation for Statistical Computing, https://www.R-project.org/.

Wilson, S.K., Depczynski, M., Fisher, R., Holmes, T.H., O'Leary, R.A. \& Tinkler, P. (2010). Habitat associations of juvenile fish at Ningaloo Reef, Western Australia: the importance of coral and algae. PLOS one, 5(12), e15185.

Woodley, J., Chornesky, E., Cliffo, P., Jackson, J., Kaufman, L., Knowlton, N., La, J., Pearson, M., Porter, J. \& Rooney, M. (1981). Hurricane Allen's impact on a Jamaican coral reef. Science, 214, 749-54. 